\title{
The effect of climate change on laying dates, clutch size and productivity of Eurasian Coots Fulica atra
}

\author{
Lucyna Halupka ${ }^{1}$ (1) $\cdot$ Beata Czyż $^{2}$ (1) $\cdot$ Carlos Moises Macias Dominguez ${ }^{2}$
}

Received: 6 November 2019 / Revised: 1 May 2020 / Accepted: 19 July 2020 / Published online: 17 September 2020

(C) The Author(s) 2020

\begin{abstract}
Climate change is affecting many living organisms; however, the responses of many of them remain unknown. In this paper, we present the results regarding the response of a bird species from the rallid family to the increased temperatures during the breeding season. We analysed the breeding data of Eurasian Coots nesting during 30 seasons between 1972 and 2019. During the study period, mean temperatures in April, the month when Coots start nesting, increased by $3.5^{\circ} \mathrm{C}$, and in months corresponding with the species breeding season by $2.6^{\circ} \mathrm{C}$. Breeding Coots advanced their earliest and median laying dates across the study period; however, the duration of their breeding season remained unchanged. We did not detect any significant temporal changes in clutch size, but clutches have become much more variable in size throughout the study period. Nest failures and production of offspring per nest did not change over the study period; however, the production of young per successful nest significantly declined. It is likely that this decline is the effect of mismatch between the period of food abundance (dipterans collected from water), and hatchling emergence, which is advanced due to change in climate. Future studies investigating the occurrence of dipteran resources at water bodies are needed to test this hypothesis.
\end{abstract}

Keywords Climate change $\cdot$ Breeding $\cdot$ Clutch size $\cdot$ Phenology $\cdot$ Eurasian Coot $\cdot$ Fulica atra

\section{Introduction}

The global mean temperature has been steadily rising across the last decades, and it seems that the current warming trend is unprecedented over decades to millennia (IPCC 2014; Houghton 2015). Changes in temperature affect other meteorological conditions, like humidity and precipitation patterns, and result in a change of climatic conditions in many places of the globe. Climatic changes affect a wide range of living organisms, including birds. Although birds remain one of the best studied groups with regard to climate change, the proportion of species

Electronic supplementary material The online version of this article (https://doi.org/10.1007/s00484-020-01972-3) contains supplementary material, which is available to authorized users.

Lucyna Halupka

lucyna.halupka@uwr.edu.pl

1 Ornithological Station, University of Wrocław, Sienkiewicza 21, 50-335 Wrocław, Poland

2 Department of Behavioural Ecology, University of Wrocław, Sienkiewicza 21, 50-335 Wrocław, Poland investigated in this context is still very low. Most avian studies related to climate-driven changes in breeding performance have concentrated on passerines (Husby et al. 2009; Vatka et al. 2011; Tarwater and Arcese 2018; Dyrcz and Czyż 2018), birds of prey and owls (Lehikoinen et al. 2011; Terraube et al. 2014), waterbirds (Moe et al. 2009; Wanless et al. 2009; Nolet et al. 2020) and waders (Smart and Gill 2003; Torti and Dunn 2005), while other groups of birds have been studied extremely rarely. Furthermore, the vast majority of studies have investigated the effect of rising temperatures on arrival and migratory dates, while the impact of climate change on population productivity and other fitness-related measures remains largely unknown.

The most clear pattern emerging from previous avian studies is that many birds advance laying dates in response to climate change (Dyrcz and Czyż 2018; Dunn 2019; Radchuk et al. 2019). The second frequently studied trait has been clutch size. In most studied species, earlier laying has not been associated with producing larger clutches (Dyrcz and Halupka 2009; Lehikoinen et al. 2011; Dunn and Møller 2014), though in some cases advanced breeding has led to increased clutch size and higher breeding success (Schaefer et al. 2006; Dunn and Møller 2010). Changes in laying dates may also affect the duration of the entire breeding season, 
leading to its shortening or extension (reviewed by Halupka and Halupka 2017), and in turn may affect changes in offspring productivity. In particular, shortening of breeding season has been found in single-brooded species, frequently relying on single food resources (Drever and Clark 2007; Najmanová and Adamík 2009). In contrast, many doublebrooded species have extended their seasons in response to climate change. They often use multiple food resources and may take advantage of a longer vegetative season, lay more clutches and hence produce more offspring annually (Halupka et al. 2008; Bulluck et al. 2013). Breeding productivity may also decrease, even if the length of breeding season remains unchanged, as a result of a mismatch between the time of peak of food resources and the time the chicks are fed by the parents (Visser et al. 2004; Drever and Clark 2007; Reed et al. 2013, but see Cresswell and McCleery 2003; Vatka et al. 2011). On the other hand, higher temperature, precipitation or humidity may be associated with higher productivity of ecosystems, and higher availability of food resources (Avery and Krebs 1984; Thomas et al. 2017). Higher temperatures may also result in important changes within the existing food chains, and affect the functioning of the whole ecosystems. For example, the shrinkage of sea-ice used for hunting by polar bears forces them to hunt on alternative terrestrial food, the eggs of colonial, ground-nesting birds (Prop et al. 2015). Similar shifts in predation pressures may be found in other ecosystems as a result of changes in vegetation cover, the rate of plant growth, altered phenology of insects, etc. (Dunn and Møller 2019).

The Eurasian Coot Fulica atra is a representative of the rail and crake bird family, the Rallidae. It breeds on freshwater lakes and ponds across the majority of Europe, Asia, Australia, and parts of Africa. Birds nesting in colder regions migrate further south and west in winter as the waters freeze, but populations in milder climates remain resident. Nests of the species have a form of platforms built of dead reeds and grasses, placed near the water's edge or on structures protruding from the water. Clutches usually contain 5-10 eggs (Cramp et al. 1980). The young leave the nest soon after hatching, but are dependent on adults for food during first weeks. In central Europe, Coots lay eggs from April to July, while in the south-west even from February to September.

In this paper, we analyse changes of breeding parameters of Eurasian Coots nesting in Poland between 1972 and 2019. The goal of this project was to find out whether climatic changes have affected laying dates, clutch size and offspring productivity.

\section{Materials and methods}

\section{Breeding data}

Breeding data of Coots nesting in Poland were obtained from the Polish nest-card scheme located at the University of
Wrocław. The cards contained the information about more than 3000 nests of the species recorded since 1972 within the whole area of Poland. However, as climatic conditions in different parts of Poland differ considerably ( 8 bioclimatic regions are distinguished; Blazejczyk 2004), differences in the annual share of records coming from areas with different climates might have biased the data. To avoid this, we included only the data from one, the largest Polish bioclimatic region (Blazejczyk 2004) comprising areas situated in central and western Poland (Fig. 1). For this reason, we excluded data from 995 cards collected in other bioclimatic regions. Furthermore, we excluded years with fewer than 10 nests for all the analyses related to laying dates (following Halupka and Halupka 2017) and with fewer than 5 nests in other analyses (following Torti and Dunn 2005; Møller et al. 2010). Finally, data on 1794 nests of the species observed during 30 breeding seasons, between 1972 and 2019, were included (data from years 1973-75, 1977, 2002-2003, 2005-2011 and 20122016 were not available for any analysis due to very low sample sizes). As not all the analysed data were available on each nest-card, sample sizes differed between the analyses. All variables related to laying dates have been calculated using the data from 1590 nests (27 seasons between 1972 and 2012), on clutch size-from 1214 nests (30 seasons, 1972-2019), and on nest success and young production on 477 nests (26 seasons between 1978 and 2019).

To estimate the annual clutch size, we assumed that complete clutches contained at least 5 eggs (c.f. Cramp et al. 1980; Rizi et al. 1999). If a nest was found during egg laying, we estimated the first-egg laying dates by backdating, assuming one egg was laid per day. If the nest with a complete clutch was found and it did not survive until hatching, we also backdated the laying date assuming the incubation lasts for

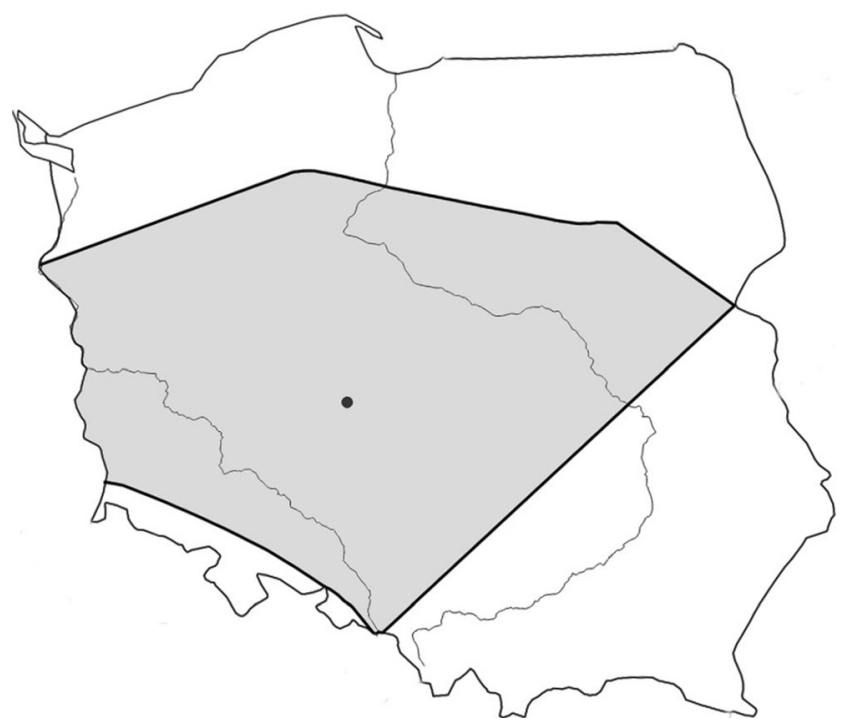

Fig. 1 Study area, the bioclimatic region IV "Central" in Poland (following Blazejczyk 2004), is marked in grey. The location of the city of Kalisz is shown as a black dot 
24 days (Lelek 1958) and the nest visit(s) occurred in mid incubation, minimising the estimation bias (Mayfield 1975; Wesołowski and Mokwa 2013). For some nests (where the drawings were provided by observers), the incubation stage was determined by immersion method (c.f. Weidinger 2001). Hatching dates were determined accurately (if observed), or estimated assuming that hatching of the first young occurred 24 days after laying of the first egg (Lelek 1958; Cramp et al. 1980).

As nest card data are subject to bias introduced by variable sampling efforts (Weidinger 2001), for each year we estimated 5th and 95th percentiles of the first-egg dates, following other authors analysing laying trends from nest-card records (e.g. Najmanová and Adamík 2009). Likewise, the interval between these dates was an estimation of the season length (c.f. Torti and Dunn 2005; Møller et al. 2010).

To assess the variability of clutch sizes, we calculated within-clutch coefficient of variation following the formula:

$C \mathrm{~V}=\frac{s \cdot 100}{\bar{\gamma}}$

where $s$ is the standard deviation of clutch size in a year and $\bar{\gamma}$ is the mean clutch size. To avoid bias of the calculated coefficient of variation due to small sample sizes in some study years, we applied the correction (Sokal and Rohlf 1995):

$C \mathrm{~V}^{a d j}=\left(1+\frac{1}{4 n}\right) \cdot C V$

where $\mathrm{CV}^{a d j}$ is the bias-adjusted coefficient of variation and $n$ is clutch size.

A nest was defined as successful if it produced at least one young (fledgling), and the annual nest success was expressed as the proportion of successful nests. For each study year, we also calculated the production of young per nest (the mean number of young that successfully left an average nest, calculated by dividing the total number of young leaving all nests by the number of nests with known outcome) and the production of young per successful nest (the mean number of young that left a successful nest in a year), following other authors (e.g. Schaefer et al. 2006; Dyrcz and Czyż 2018).

\section{Meteorological data}

Weather data were obtained online from TuTiempo Network (https://en.tutiempo.net/climate) for the city of Kalisz (TuTiempo 2020), located in the centre of the study area $(51.78 \mathrm{~N}, 18.08 \mathrm{E})$. We used mean diurnal temperatures (in Celsius degrees) and average relative humidity (in \%) for months corresponding with the species breeding season (April-July). Similar data were obtained for precipitation (monthly sums in $\mathrm{mm}$ ).

\section{Statistical analysis}

To study the changes in the timing of breeding, we analysed (1) the earliest laying date observed in a season; (2) the median laying date calculated for all nests in the season, including second broods as well as re-nests after previous nest failure; and (3) the latest laying date and (4) the length of the laying period (the time between the date of laying of the first egg in the earliest and the latest nest in a season). The analysis of reproductive parameters included clutch size, nest success (i.e. the proportion of nests that produced at least one hatchling) and mean production of young per nest and per successful nest.

In the analyses of changes in breeding parameters over the study period (1972-2019), we used Mann-Kendall trend test corrected for serial dependence using the $\mathrm{R}$ package modifiedmk (Patakamuri and O'Brien 2019). Sen's slope estimator was used for computing the changes in mean temperatures, humidity and breeding season advancement across the study years. We used partial Mann-Kendall test (Libiseller and Grimvall 2002) to analyse whether the detected trends were caused by significant trends in the temperatures and humidity. The analysis was done with the $\mathrm{R}$ package trend (Pohlert 2018) and different mean temperatures and humidity were used depending on a tested breeding parameter (see Table 1). We also calculated Kendall correlation coefficients between the breeding parameters with a significant trend over time and meteorological data. $P$ values of multiple tests were corrected for multiple comparisons using Holm method (Holm 1979). Statistical analyses were performed using R (version 3.6.3) software (R Development Core Team 2020).

\section{Results}

\section{Changes in meteorological data}

Mean monthly temperatures in April, May, June and July increased significantly across the study period (MannKendall test, April: $\tau=0.46, p=0.001$, May: $\tau=0.21, p=$ 0.036 , June: $\tau=0.31, p=0.002$, July: $\tau=0.33, p<0.001$ ) and the trend for the whole breeding season was also significant (Mann-Kendall test, April-July: $\tau=0.52, p<0.001$ ). The increase equalled $2.6^{\circ} \mathrm{C}$ for the whole breeding season, and $3.5^{\circ} \mathrm{C}$ for April, when Coots start nesting (Fig. 2). We have not detected any significant trend in precipitation levels, either for monthly totals or for the whole breeding season. Mean monthly humidity in April and July slightly decreased throughout the study period, but not in May and June (Mann-Kendall test, April: $\tau=-0.22, p=0.03$, May: $\tau=-$ $0.14, p=0.15$, June: $\tau=-0.14, p=0.16$, July: $\tau=-0.28, p=$ 0.006 ), while the trend for the whole breeding season was also significant (Mann-Kendall test, April-July: $\tau=-0.28, p=$ 
Table 1 Values of partial MannKendall test statistic for relationships between significant trends in Coot breeding parameters and significant trends in climatic variables

\begin{tabular}{lll}
\hline Breeding parameter & April/April-July temperature $(\mathrm{z}, \mathrm{p})$ & April/April-July humidity \\
\hline Earliest laying date & $-2.86,0.024$ & $-3.56,0.004$ \\
Median laying date & $-2.59,0.028$ & $-3.56,0.004$ \\
Median hatching date & $-2.62,0.028$ & $-3.56,0.004$ \\
Clutch CV & $2.70,0.028$ & $3.42,0.004$ \\
Production per successful nest & $-1.59,0.113$ & $-2.80,0.025$ \\
\hline
\end{tabular}

Earliest laying date trend was tested for April temperature/humidity trends while the rest of the breeding parameters were tested for seasonal (April-July) climatic data trends. $P$ values were adjusted for multiple comparisons using Holm method
0.005). The decrease in humidity equalled $6 \%$ for the whole breeding season, $7 \%$ for April and $8 \%$ for July.

\section{Changes in breeding parameters}

During the study period, Eurasian Coots laid their eggs between 31 March and 14 July, but clutches started in July were very rare ( 4 cases, $0.22 \%$ of all nests). In different years, the first eggs in the earliest annual clutches were laid between 31 March and 24 April. Throughout the study period, Coots started laying their earliest clutches progressively earlier (Mann-Kendall test: $\tau=-0.49, p<0.001, n=27$ ); Fig. 3 . Likewise, median annual laying dates have become significantly advanced by about 20 days (Mann-Kendall test: $\tau=-$ $0.48, \mathrm{p}<0.001, n=27$ ); Fig. 3. Median annual hatching dates advanced by about 18 days and the temporal trend was significant (Mann-Kendall test: $\tau=-0.48, p<0.001, n=27$ ). In contrast, the latest annual first-egg dates did not change
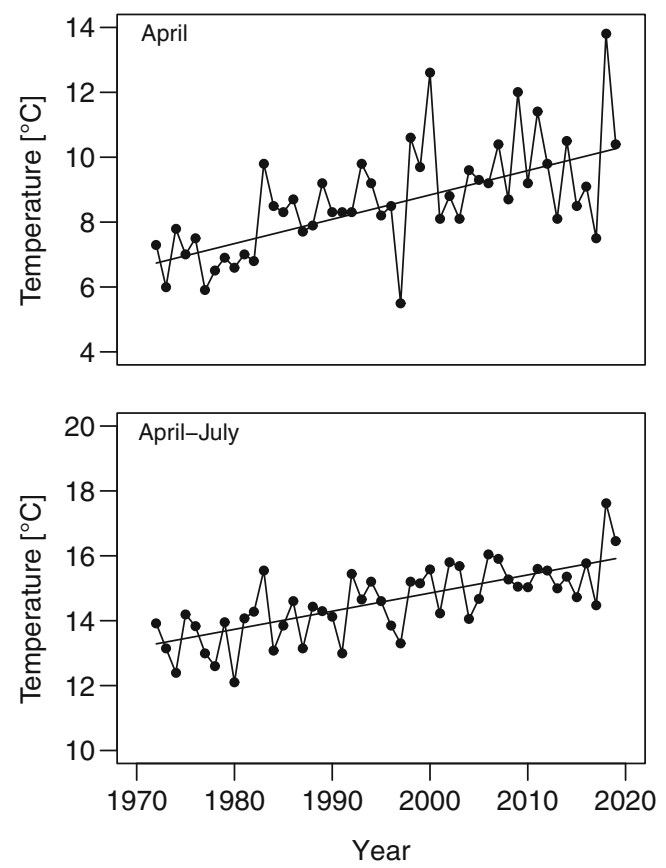

Fig. 2 Mean temperatures of April and April-July in central Poland between 1972 and 2019 significantly throughout the study period (Mann-Kendall test: $\tau=-0.03, p=0.85, n=27)$. We did not find any significant changes in the duration of laying period (Mann-Kendall test: $\tau=0.19, p=0.17, n=27)$. The trends in the timing of breeding (earliest and median laying dates and median hatching date) were significantly related to the trends in temperature and humidity, tested for April (earliest laying date) and April-July (median laying and hatching dates) temperature and humidity (Table 1). Median laying and median hatching dates were negatively correlated with seasonal (April-July) temperatures (respectively $\tau=-0.43, p=0.03, n=27$, and $\tau=-0.40, p=0.042, n=27$ ), while the earliest laying date was not significantly correlated to April meteorological data (all $p>0.05$ ).

Complete clutches of Eurasian Coots usually contained seven eggs (range 5-14), and the mean annual values ranged 6.24-8.19. We have not detected any significant changes in clutch size throughout the study years (Mann-Kendall test:
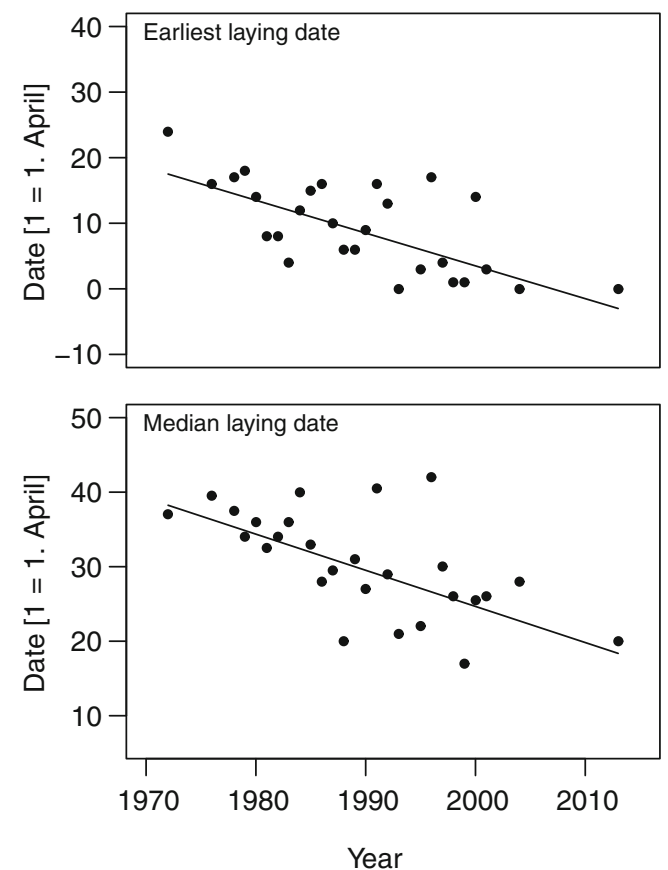

Fig. 3 Changes in the earliest and median first-egg laying dates of the Eurasian Coots 
$\tau=0.18, p=0.261, n=30$ ). However, clutch sizes have become significantly more variable across the study period (Mann-Kendall test: $\mathrm{CV}^{\text {adj }}$ : $\tau=0.46, p=0.006, n=30$ ). The trends in the coefficient of variation in clutch size were related to the trend in April-June temperature and humidity (Table 1). Nonetheless, we did not find the significant correlation between the coefficient of variation in clutch size and any of the seasonal (April-July) climatic data (all $p>0.05$ ).

Nest success varied widely between years, but we did not find a significant temporal trend (Mann-Kendall test: $\tau=0.08, p=$ $0.591, n=26$ ). As a result, the production of young per nest also did not show any significant trend across years (Mann-Kendall test: $\tau=0.06, p=0.674, n=25$ ). However, we found a negative significant trend in the production of young per successful nest (Mann-Kendall test: $\tau=-0.41, p=0.003, n=26$ ), which was significantly related to the trend in April-July humidity (Table 1). Nonetheless, no significant correlation between production of young per successful nest and any seasonal (April-July) meteorological variables was found (all $p>0.05$ ).

\section{Discussion}

In response to much higher temperatures during the breeding season, Eurasian Coots significantly advanced their laying dates. This is a result frequently observed in other bird species (Halupka et al. 2008; Vatka et al. 2011; Dyrcz and Czyż 2018; Smith et al. 2020) but not all (Nielsen and Møller 2006; Wright et al. 2009).

Because the earliest laying dates have advanced and we have not found any significant changes in the latest laying dates, this should result in the lengthening of the laying period of the species (Halupka and Halupka 2017). However, we did not observe the extension of the laying period (and hence the whole breeding season) throughout the study period. It seems that the cessation of the breeding season of Eurasian Coots was quite variable among years, and hence no consistent pattern in the season length has been detected (see Dyrcz and Halupka 2009). This result contradicts the assumption that multi-brooded species with a long breeding season, like the Coot (Cramp et al. 1980), should take advantage of a longer growing season and extend their breeding seasons (Dunn and Winkler 2010). However, although Coots are able to re-nest or even raise second broods and their season is quite long (Cramp et al. 1980), they do not belong to typical multi-brooded species, regularly raising two or three clutches annually (Dhondt 2010). Furthermore, earlier studies performed in the species have revealed a convex seasonal pattern in the production of young per brood. The experiments confirmed a causal relationship between laying date and fledging success, and experimental delay in the timing of breeding in the second half of the season resulted in a decline of breeding success (Brinkhof et al. 1993). These results suggest that Eurasian Coots may be strongly dependant on the optimal, short-term food resources for their young (Horsfall 1984), and hence may not benefit from the prolongation of the breeding season.

This study is another one to reveal that clutch size did not increase with the advancement of laying dates. Some papers on climate change hypothesised that in species in which the laying date is correlated with clutch size, advanced breeding may result in an increased number of eggs (Dunn and Winkler 2010). This was indeed found in some species (e.g. Schaefer et al. 2006), but not in the majority of studied ones (Dunn and Møller 2014). However, we found an interesting trend, showing that the coefficient of clutch variation increased in time, indicating that clutches have become more variable in size in recent years. This may indirectly suggest that foraging conditions for breeding females have become more variable across the breeding season in recent years.

We found a negative trend in the production of young per successful nest though clutch size did not change significantly across years. This suggests that partial losses increased throughout the study period. The most likely these losses occurred soon after hatching: the number of hatched eggs was usually estimated based on the number of young observed with adults soon after hatching. First 2 weeks after hatching and nest leaving are critical for survival of young Coots, and many of them die during this period (Horsfall 1984; Brinkhof et al. 1993). Our analysis suggests that mortality of hatchlings may have increased throughout the study period; however, the underlying mechanisms remain unclear. One possible mechanism is associated with a mismatch between the occurrence of food for the young and the time when young need most food (Visser et al. 2004; Thomas et al. 2001). During 2 weeks after hatching, young Coots are fed by their parents predominantly with dipterans picked up from the water surface, and this time period is critical for their survival (Horsfall 1984). The dipterans are characterised by a convex seasonal pattern of abundance (Horsfall 1984). Previous experimental studies revealed that the young hatched before and after the peak of dipteran abundance suffered lower survival, suggesting that proper timing is crucial for survival of young Coots (Brinkhof et al. 1993). More than 25 years ago, when these experiments were conducted, most young hatched during the peak of dipteran prey. It is very likely that today these two phenological events are not synchronised: the development of invertebrates is strongly temperature-dependant (Regniere et al. 2012; Esbjerg and Sigsgaard 2019), and the increase in spring temperatures has been very strong in the study area. Furthermore, many studies suggest that advancements in insect phenology are stronger than the ones of birds (e.g. Polgar et al. 2013). Therefore, it is likely that nowadays the peak of dipteran abundance is advanced in relation to the Coot phenology, resulting in food shortage for the Coot young and their declined survival. Such unequal phenological shifts at different ecological levels resulting in lower offspring production have been reported for several other species (e.g. Drever and Clark 2007; Van der Jeugd et al. 2009; Donelly et al. 2011; Dunn et al. 2011; Te Marvelde et al. 2011) and 
probably are more widespread than we supposed. The mismatch hypothesis seems to explain the increased mortality of young Coots; however, at present, we have no data to estimate shifts in diptera abundance in pond ecosystems, so we cannot test this hypothesis. It is also possible that the mortality of young Coots has different reasons (e.g. higher predation rate from the new, introduced predators, e.g. the American mink, changing water levels) or several factors are involved.

\section{Conclusions}

Climate change has strongly affected the reproductive biology of Eurasian Coots. The birds started nesting significantly earlier but their breeding season length remained unchanged. Although the clutch size and nest success have not changed across years, the productivity of successful nests has significantly declined, probably as a result of mismatch between the occurrence of dipterans in water (the main food for young Coots) and the Coot breeding phenology. Future studies are needed to better understand the mechanisms explaining partial losses in the Coot offspring.

Acknowledgements We would like to thank to all collaborators of nestcard scheme at the University of Wrocław for their contribution to data collection. Special thanks go to Aleksandra Czylok for her help in the fieldwork in 2018 and 2019.

Funding The work was supported by the grant obtained from the National Science Centre, Poland (project nr 2017/27/B/NZ8/00465).

\section{Compliance with ethical standards}

The analyses and procedures of this research conformed to the current laws of Poland. Permits to conduct the analysis of nest-card data were not required as we analysed previously collected breeding data. The fielwork in the nature reserve "Stawy Milickie" in 2018-19 was conducted under the permit of the Regional Directorate for Nature Protection in Wrocław (WPN.6205.26.2018.MR.2).

Conflict of interest The authors declare that they have no conflict of interest.

Open Access This article is licensed under a Creative Commons Attribution 4.0 International License, which permits use, sharing, adaptation, distribution and reproduction in any medium or format, as long as you give appropriate credit to the original author(s) and the source, provide a link to the Creative Commons licence, and indicate if changes were made. The images or other third party material in this article are included in the article's Creative Commons licence, unless indicated otherwise in a credit line to the material. If material is not included in the article's Creative Commons licence and your intended use is not permitted by statutory regulation or exceeds the permitted use, you will need to obtain permission directly from the copyright holder. To view a copy of this licence, visit http://creativecommons.org/licenses/by/4.0/.

\section{References}

Avery MI, Krebs JR (1984) Temperature and foraging success of Great Tits Parus major hunting for spiders. Ibis 126:33-38

Blazejczyk K (2004) Climate and bioclimate of Poland. In: Natural and human environment of Poland. A geographical overview (ed. by M Degórski). Polish Academy of Sciences, Inst. of Geography and Spatial Organization. Polish Geographical Society, Warsaw 2006: $31-48$

Brinkhof MWG, Cavé AJ, Hage FJ, Verhulst S (1993) Timing of reproduction and fledging success in the coot Fulica atra: evidence for causal relationship. J Anim Ecol 62:577-587

Bulluck L, Huber S, Viverette C, Blem C (2013) Age-specific responses to spring temperature in a migratory songbird: older females attempt more broods in warmer springs. Ecol Evol 3:3298-3306

Cramp S, Simmons KEL, Gillmore R, Hollom PAD, Hudson R, Nicholson EM, Ogilvie MA, Olney PJS, Roselaar CS, Voous KH, Wallace DIM, Wattel J (1980) The birds of the Western Palearctic, vol 2. Oxford University Press, Oxford

Cresswell W, McCleery R (2003) How great tits maintain synchronisation of their hatch date with food supply in response to long-term variability in temperature. J Anim Ecol 72:356-366

Dhondt AA (2010) Broodedness, not latitude, affects the response of reproductive timing of birds to food supplementation. J Ornithol 151:955-957

Donelly A, Cafarra A, O'Neill BF (2011) A review of climate-driven mismatches between interdependent phenophases in terrestrial and aquatic ecosystems. Int J Biometeorol 55:805-817

DreverMC, Clark RG (2007) Spring temperature, clutch initiation date and duck nest success: a test of mismatch hypothesis. J Anim Ecol 76:139-148

Dunn PO (2019) Changes in timing of breeding and reproductive success in birds. In: Dunn PO, Møller AP (eds) Effects of climate change on birds. Oxford University Press, Oxford

Dunn PO, Møller AP (2014) Changes in breeding phenology and population size in birds. J Anim Ecol 82:729-739

Dunn PO, Møller AP (2019) Effects of climate change on birds. Oxford University Press, Oxford

Dunn PO, Winkler DW (2010) Effects of climate change on timing of breeding and reproductive success in birds. In: Møller AP, Fiedler W, Berthold P (eds) Effects of climate change on birds. Oxford University Press, Oxford, pp 113-128

Dunn PO, Winkler DW, Whittingham LA, Hannon SJ, Robertson RJ (2011) A test of the mismatch hypothesis: how is timing of reproduction related to food abundance in an aerial insectivore? Ecology 92:450-461

Dyrcz A, Czyż B (2018) Advanced breeding time in line with climate did not affect productivity of Great Reed Warblers Acrocephalus arundinaceus despite the shortening of the nestling period. Acta Ornithol 53:13-22

Dyrcz A, Halupka L (2009) The response of the Great Reed Warbler Acrocephalus arundinaceus to climate change. J Ornithol 150:39-44

Esbjerg P, Sigsgaard L (2019) Temperature dependent growth and mortality of Agrotis segetum. Insects 10:7

Halupka L, Halupka K (2017) The effect of climate change on the duration of avian breeding seasons: a meta-analysis. Proc R Soc B 284: 20171710

Halupka L, Dyrcz A, Borowiec M (2008) Climate change affects breeding of reed warblers Acrocephalus scirpaceus. J Avian Biol 39:95-100

Holm S (1979) A simple sequentially rejective multiple test procedure. Scand J Stat 6:65-70

Horsfall JA (1984) Brood reduction and brood division in coots. Anim Behav 32:216-225

Houghton J (2015) Global warming: the complete briefing, Fifth edn. Cambridge University Press, Cambridge 
Husby A, Kruuk LEB, Visser ME (2009) Decline in the frequency and benefits of multiple brooding in great tits as a consequence of a changing environment. Proc R Soc B 276:1845-1854

IPCC (2014) Fifth assessment report

Lehikoinen A, Ranta E, Pietiäinen H, Byholm P, Saurola P, Valkama J, Huitu O, Henttonen H, Korpimäki E (2011) The impact of climate and cyclic food abundance on the timing of breeding and brood size in four boreal owl species. Oecologia 165:349-355

Lelek A (1958) Contribution to the bionomy of the Coot (Fulica atra L.). Folia Zool 7:143-168

Libiseller C, Grimvall A (2002) Performance of partial Mann-Kendall tests for trend detection in the presenceof covariates. Environmetrics 13:71-84

Mayfield HF (1975) Suggestions for calculating nest success. Wilson Bull 87:456-466

Moe B, Stempniewicz L, Jakubas D, Angelier F, Chastel O, Dinessen F, Gabrielsen GW, Hanssen F, Karnovsky NJ, Rønning B, Welcker J, Wojczulanis-Jakubas K, Bech C (2009) Climate change and phenological responses of two seabird species breeding in the high-Arctic. Mar Ecol Prog Ser 393:235-246

Møller AP, Flensted-Jensen E, Klarborg K, Mardal W, Nielsen JT (2010) Climate change affects the duration of the reproductive seasons in birds. J Anim Ecol 79:777-784

Najmanová L, Adamík P (2009) Effect of climatic change on the duration of the breeding season in three European thrushes. Bird Study 56:349-356

Nielsen JT, Møller AP (2006) Effects of food abundance, density and climate change on reproduction in the sparrowhawk Accipiter nisus. Oecologia 149:505-518

Nolet BA, Schreven KHT, Boom MP, Lameris KL (2020) Contrasting effects of the onset of spring on reproductive success of Arcticnesting geese. Auk 137. https://doi.org/10.1093/auk/ukz063

Patakamuri SK, O'Brien N (2019) Modifiedmk: modified versions of Mann Kendall and Spearman's rho trend tests. $\mathrm{R}$ package version 1.4.0. https://CRAN.R-project.org/package=modifiedmk

Pohlert T. (2018) Trend: non-parametric trend tests and change-point detection. R package version 1.1.1. https://CRAN.R-project.org/ package $=$ trend

Polgar CA, Primack RB, Williams EH, Stichter S, Hitchcock C (2013) Climate effects on the flight period of Lycaenid butterflies in Massachusetts. Biol Conserv 160:25-31

Prop J, Aars J, Bårdsen B-J, Hanssen SA, Bech C, Bourgeon S, de Fouw J, Gabrielsen GW, Lang J, Noreen E, Oudman T, Sittler B, Stempniewicz L, Tombre I, Wolters E, Moe B (2015) Climate change and the increasing impact of polar bears on bird populations. Front Ecol Evol 3:33

R Development Core Team (2020) R: a language and environment for statistical computing. R Foundation for Statistical Computing, Vienna URL https://www.R-project.org/

Radchuk V, Reed T, Teplitsky C, van de Pol M, Charmantier A, Hassall C, Adamík P, Adriaensen F, Ahola MP, Arcese P, Miguel Avilés J, Balbontin J, Berg KS, Borras A, Burthe S, Clobert J, Dehnhard N, de Lope F, Dhondt AA, Dingemanse NJ, Doi H, Eeva T, Fickel J, Filella I, Fossøy F, Goodenough AE, Hall SJG, Hansson B, Harris M, Hasselquist D, Hickler T, Joshi J, Kharouba H, Martínez JG, Mihoub JB, Mills JA, Molina-Morales M, Moksnes A, Ozgul A, Parejo D, Pilard P, Poisbleau M, Rousset F, Rödel MO, Scott D, Senar JC, Stefanescu C, Stokke BG, Kusano T, Tarka M, Tarwater CE, Thonicke K, Thorley J, Wilting A, Tryjanowski P, Merilä J, Sheldon BC, Pape Møller A, Matthysen E, Janzen F, Dobson FS, Visser ME, Beissinger SR, Courtiol A, Kramer-Schadt S (2019) Adaptive responses of animals to climate change are most likely insufficient. Nat Commun 10:3109

Reed T, Jenouvrier S, Visser ME (2013) Phenological mismatch strongly affects individual fitness but not population demography in a woodland passerine. J Anim Ecol 82:131-144
Regniere J, Powell J, Bentz B, Nealis V (2012) Effects of temperature on development, survival and reproduction of insects: experimental design, data analysis and modeling. J Insect Physiol 58:634-647

Rizi H, Benyacoub S, Chabi Y, Bańbura J (1999) Nesting and reproductive characteristics of coots Fulica atra breeding on two lakes in Algeria. Ardeola 46:179-186

Schaefer T, Ledebur G, Beier J, Leisler B (2006) Reproductive responses of two related coexisting songbird species to environmental changes: global warming, competition, and population sizes. J Ornithol 147:47-56

Smart J, Gill JA (2003) Climate change and the potential impact on breeding waders in the UK. Wader Study Group Bull 100:80-85

Smith RJ, Hatch MI, Carey M (2020) Arrival timing and the influence of weather experienced during the nonbreeding and breeding periods on correlates of reproductive success in female field sparrows (Spizella pusilla) breeding in northeastern Pennsylvania, USA. Int J Biometeorol. https://doi.org/10.1007/s00484-020-01905-0

Sokal RR, Rohlf FJ (1995) Biometry: the principles and practise of statistics in biological research. WH Freeman and Co, New York

Tarwater CE, Arcese P (2018) Individual fitness and the effects of a changing climate on the cessation and length of the breeding period using 34-year study of a temperate songbird. Glob Chang Biol 24: $1212-1223$

Te Marvelde L, Webber SL, Meijer HA, Visser ME (2011) Mismatched reproduction is energetically costly for chick feeding female great tits. Funct Ecol 25:1302-1308

Terraube J, Villers A, Ruffino L, Iso-Iivari L, Henttonen H, Oksanen T, Körpimaki E (2014) Coping with fast climate change in northern ecosystems: mechanisms underlying the population-level responses of a specialist avian predator. Ecography 37:1-10

Thomas DW, Blondel J, Perret P, Lambrechts MM, Speakman JR (2001) Energetic and fitness costs of mismatching resource supply and demand in seasonally breeding birds. Science 291:2598-2600

Thomas RJ, Vafidis JO, Medeoros RJ (2017) Climatic impacts on invertebrates as food for vertebrates. In: Johnson SN, Jones TH (eds) Global climate change and terrestrial invertebrates. WileyBlackwell, New Jersey, pp 295-316

Torti VM, Dunn PO (2005) Variable effects of climate change on six species of North American birds. Oecologia 145:486-495

TuTiempo (2020) Climate data: Kalisz. Available from: https://en. tutiempo.net/climate/ws-124350.html. Last accessed on 7 April 2020

Van der Jeugd HP, Eichhorn G, Litvins KE, Stahl J, Larsson K, Van der Graaf A, Drent RH (2009) Keeping up with early springs: rapid range expansion in an avian herbivore incurs a mismatch between reproductive timing and food supply. Glob Chang Biol 15:10571071

Vatka E, Orell M, Rytkönen S (2011) Warming climate advances breeding and improves synchrony of food demand and food availability in a boreal passerine. Glob Chang Biol 17:3002-3009

Visser ME, Both C, Lambrechts MM (2004) Global climate change leads to mistimed avian reproduction. Adv Ecol Res 35:89-109

Wanless S, Frederiksen M, Walton J, Harris MP (2009) Long-term changes in breeding phenology of two seabird colonies in the western North Sea. Ibis 151:274-285

Weidinger K (2001) Laying dates and clutch size of open-nesting passerines in the Czech Republic: a comparison of systematically and incidentally collected data. Bird Study 48:38-47

Wesołowski T, Mokwa T (2013) Cuckoo's Cuculus canorus hosts and timing of breeding in Poland: analysis of ringing and nest records' data. Ornis Polonica 54:159-169

Wright LJ, Hoblyn RA, Green RE, Bowden CGR, Mallord JW, Sutherland WJ, Dolman PM (2009) Importance of climatic and environmental change in the demography of multi-brooded passerine, the woodlark Lullula arborea. J Anim Ecol 78:1191-1202 